\section{Animal health surveillance by quadrant - A new "intelligent" agricultural surveillance system}

\author{
Vigilância em saúde animal por quadrante - Um novo sistema \\ "inteligente" de vigilância agropecuária
}

\author{
Francisco Bezerra de Carvalho Neto ${ }^{1}$ (D), Franco Zanandreis ${ }^{1}$ (D) \& Clayton Bernardinelli Gitti ${ }^{2}$ (D) \\ 'Veterinary. Agência Estadual de Defesa Sanitária Animal e Vegetal - IAGRO, Campo Grande, MS, Brasil \\ Veterinary, Dr. Departamento de Epidemiologia e Saúde Pública, Universidade Federal Rural do Rio de Janeiro - UFRRJ, \\ Seropédica, RJ, Brasil
}

\begin{abstract}
Brazil is the world's largest beef exporter and the state of Mato Grosso do Sul in Brazil is of utmost importance for food production of animal origin. To ensure livestock health, the Agricultural Defense Services of all federative units perform surveillance activities, though not as effectively as they should, following the procedures defined by the Ministry of Agriculture, Livestock and Supply. This study aims to present a new health surveillance system adopted in Mato Grosso do Sul that involves mapping each municipality into quadrants and ranking those quadrants by risk levels. Surveillance actions are then planned such that all quadrants receive homogeneous care. These actions are tracked and registered through GPS devices and the data are assessed using satellite image analyzing softwares. Finally, the actions are audited and the results are analyzed monthly for future action planning. The implementation of the new system resulted in the following: surveillance actions ceased to be performed on demand and started to cover not only the areas closer to the local office but also the distant areas; registration and regular updation of sanitary program data made it easy to audit surveillance actions, allowing all actions of the Health Defense Services to be controlled and monitored. It is expected that, once this system is implemented in other federative units, it will give a differential advantage to the Brazilian Health Defense Services.
\end{abstract}

Keywords: livestock surveillance, quadrant, Mato Grosso do Sul.

\section{RESUMO}

O Brasil é o maior exportador mundial de carne e o Mato Grosso do Sul éum dos estados de maior relevância na produção animal. Para assegurar a sanidade dos rebanhos, os serviços de defesa agropecuária de todas as unidades federativas executam atividades de vigilância seguindo modelos preconizados pelo Ministério da Agricultura Pecuária e Abastecimento (MAPA) mas que não são tão eficientes. Este trabalho tem como objetivo mostrar um novo sistema de vigilância agropecuária que foi implementado no estado do Mato Grosso do Sul e Campo Grande servindo como projeto piloto, onde cada município foi mapeado em quadrantes, redimensionados geograficamente e realizada a classificação de risco de cada um. É realizado um planejamento anual de atividades das Unidades Epidemiológicas através de análise de imagens de satélitee mapas, definindo-se o perfil epidemiológico do quadrante e a quantidade de visitas, onde todos os quadrantes do município recebem a vigilância da defesa agropecuária, o calendário de execução das atividades e as projeções dos custos operacionais. As ações são rastreadas e registradas a partir do uso compulsório de aparelhos GPS. Dessa forma, as ações são transparentes, confiáveis e seu resultado pode ser analisado mensalmente para o planejamento de futuras ações. Como resultado, as ações de vigilância deixaram de ser executadas apenas por demanda e passaram a ser ativas abrangendo todas as áreas dos municípios e não somente aquelas mais próximas do escritório local; as informações cadastrais e dos programas sanitários foram atualizadas e as atividades passaram a ser totalmente transparentes e confiáveis, o que permitiu controlar e acompanhar todas as ações operacionais dos serviços de defesa sanitária. Há o entendimento que se implantado em outras unidades federativas, será um diferencial nos Serviços de Defesa Sanitária do Brasil.

Palavras-Chave: vigilância agropecuária, Quadrante, Mato Grosso do Sul.
How to cite: Carvalho Neto F.B., Zanandreis F., Gitti C. B. (2020). Animal health surveillance by quadrant - A new "intelligent" agricultural surveillance system. Brazilian Journal of Veterinary Medicine, 42, e108020. https://doi.org/10.29374/2527-2179 bjvm108020

Financial support: Agência Estadual de Defesa Sanitária Animal e Vegetal - IAGRO

Conflict of interests: No conflict of interests declared concerning the publication of this article.

Received: October 03, 2019.

Accepted: February 21, 2020

The study was performed project was implemented in the Municipality of Campo Grande - capital of Mato Grosso do Sul State.

\section{*Correspondence}

Francisco Bezerra de Carvalho Neto

Inspetoria Regional IAGRO de Campo Grande,

Agência Estadual de Defesa Sanitária Animal e Vegetal - IAGRO

Rua Antônio Maria Coelho, 1836

CEP 79002-221 - Centro Campo Grande (MS)

Brasil

E-mail: cabrabom.bomcabra@gmail.com
Copyright Carvalho Neto et al. This is an Open Access article distributed under the terms of the Creative Commons Attribution Non-Commercial License which permits unrestricted non-commercial use, distribution, and reproduction in any medium provided the original work is properly cited. 


\section{Introduction}

Brazil is one of the largest producers and exporters of meat in the world. According to the Brazilian Association of Meat Exporting Industries (ABIEC), the volume of beef exported by Brazil throughout 2018 set a new record, registering an 11\% growth compared to 2017 (Associação das Indústrias Exportadoras de Carne, 2019a).

The state of Mato Grosso do Sul (MS) has a large share in food production of animal origin, representing the $4^{\text {th }}$ largest cattle herd in Brazil with about 21.8 million heads and is responsible for the slaughter of 4.33\% and 3.23\% of pigs and poultry, respectively (Associação das Indústrias Exportadoras de Carne, 2019b).

To ensure animal health and food production, a well-structured, efficient, and able veterinary service is required for the detection and early adoption of disease control and eradication measures. In agreement with the World Organization for Animal Health (OIE), the Brazilian veterinary service, responsible for animal health policy, is composed of the Ministry of Agriculture, Livestock and Supply (MAPA) and the agricultural secretariats in the federative units, sharing with the private sector the responsibilities to apply the measures aimed at improving animal health (Brasil, 2019a).

It is the responsibility of each state's Agricultural Defense Service to plan and execute activities to prevent and control agricultural diseases and pests (Brasil, 2006). One of the main tools used for this purpose is the surveillance of major livestock diseases, the list of which was updated in 2013 by MAPA (Brasil, 2013), aimed at demonstrating the presence, absence, or distribution of disease or infection, or detecting the presence of exotic or emerging diseases as soon as possible. The type of surveillance conducted depends on the results required for decision making (Organização Mundial de Saúde Animal, 2019).

Disease monitoring and surveillance are essential for the official veterinary services of a country, and various forms and tools can be used for this, depending on the purpose of the analysis (Eidt et al., 2015).

In general, there are two ways of carrying out disease surveillance in herds: active surveillance, such as the surveillance of carcasses in slaughterhouses, implementation of epidemiological surveys, or surveillance of rural properties and/or agricultural events, aimed at identifying the characteristic signs of disease presence in individuals or populations, among others; and passive surveillance, carried out with the participation of veterinary doctors, laboratories, and the general population for the detection and reporting (to the official veterinary service) of suspected diseases in herds (Organização Mundial de Saúde Animal, 2019).

For the surveillance system to be effective, monitoring should be carried out at a frequency that reflects the pathogens' biology and the risk of their introduction into an epidemiological unit, which should be defined such that it meets the surveillance objectives. The epidemiological unit should be chosen taking into consideration factors such as animal species, aptitude, distribution and concentration of populations, degree of immunity, among other characteristics (Organização Mundial de Saúde Animal, 2019). For greater monitoring effectiveness, geospatial analysis can be used as it contributes to prevent the entry and establishment of quarantine diseases in Brazil and supports the planning of containment and control measures (Mingoti \& Spadotto, 2016).

The present study was developed and executed by Francisco Bezerra de Carvalho Neto and Franco Zanandreis, while performing their duties as State Agricultural Inspectors, with the support of the State Agency for Animal and Plant Health Defense (IAGRO), involving innovation and implementation of new tools for field work and planning.

The current animal health surveillance system in Brazil is similar in all federative units, with some occasional updates, executed either passively when provoked by complaints, damages, or diagnostic evidence with proof, or in an active punctual manner without homogeneous geographic distribution in the Local Sanitation Care Units or strategic planning, and is hence obsolete. It is financed by the public sector, usually with scarce human and financial resources, without any planned operating costs and financial contribution.

The effectiveness of each state's epidemiological surveillance system is evaluated by the Coordination of Evaluation and Improvement of Veterinary Services (CASV) of MAPA, through the continuous monitoring of indicators and face-to-face audits for the establishment of quality parameters and system improvement (Brasil, 2019b). 
The use of Geographic Information System (GIS) in the field of animal health surveillance has increased considerably over the past 20 years, motivated in part by the enhanced use of epidemiological tools in veterinary services, and developing and improving GIS technologies both at the field (use of geolocation devices) and central (use of GIS software and spatial analysis) level. The combined use of these tools helps to intelligently and dynamically optimize the basic activities of the official defense services, such as property registration, identification of risk properties, activity planning, vaccination campaign logistics, sample design and execution, etc. (Buzanovsky et al., 2015).

\section{Objectives}

The objective of this work was to report the initial results of a new animal health surveillance system, which is based on capillarity increase, and suggest improvements and modifications in the planning and execution of surveillance actions in the field.

\section{Material and methods}

The new surveillance system is based on the resizing of the area of operation; that is, the number of quadrants to be served by the Local Sanitation Care Units, the analysis and classification of health risks of each quadrant, and the annual planning and execution of actions to be carried out by the Regional and Local Units.

In order to implement this new system, the following steps were taken: training personnel in the use of GPS receivers and different softwares for editing maps and satellite images; creation of the quadrant selection protocol for resizing; geographic resizing of IAGRO's Regional Units, with the spatial distribution of the state of MS in quadrants; creation of the epidemiological unit called quadrant; analysis and identification of the road and land structure of each quadrant; and planning of surveillance actions.

To evaluate the "Animal Health Surveillance by Quadrant" system, a pilot project was implemented in the Municipality of Campo Grande - capital of MS using the structure of its Local Veterinary Unit, from $3^{\text {rd }}$ to $47^{\text {th }}$ epidemiological week of 2018.

The Animal Health Surveillance by Quadrant system was developed in five stages:

In the first stage, the public servants underwent a training course titled "The importance and application of GPS, GPS TrackMaker, and Google Earth in Sanitation Defense." It involved learning how to use GPS receiver, GPS TrackMaker ${ }^{\circledR}$, Google Earth ${ }^{\circledR}$, Google Maps ${ }^{\circledR}$, BaseCamp ${ }^{\circledR}$, and other internet applications.

From July 2016 to August 2017, 17 training sessions were held and 279 IAGRO employees (84.5\%) were trained. Eight people, 2 from the State Enterprise Management Agency (AGESUL), 1 from the Mato Grosso Agricultural Defense Institute (INDEA/MT), 1 from the Campo Grande Military Police (PMCG), 1 from MAPA, 2 from the Federal University of Mato Grosso do Sul, and 1 from the Luiz Chagas Radio and Television Foundation - FERTEL, also attended the sessions, thus, totaling 287 people. Of the 11 Regional Inspectors, 6 participated in the training. Of the total, 172 were State Agricultural Inspectors, 89 were Agents (74 Agricultural Inspector and 15 Agricultural Services Agents), 15 were Assistants of Agricultural Services, and 3 were State Agricultural Managers. The objective was to train public servants to use tools with specific applications to undertake the sanitary defense services, with emphasis on configurations, interactions with other applications; mapping and locating "Sanitary Points of Interest" (PIS); execution of field "service order" or planning activities; distance calculation; determination and management of risk areas; real-time navigation; research, editing, management, and data storage; and planning of intelligent sanitary surveillance.

In the second stage, a selection tool was chosen to geographically resize IAGRO's Regional Units in a uniform and standardized manner, so that there would be no interference in the differentiated areas of biomes (Atlantic Forest, Pantanal, and Plateau) and sanitary regions (High Surveillance Zone, Pantanal, and Plateau).

For this purpose, the geometric figure of a square quadrilateral was selected. Named "quadrant," it was defined as a "predetermined geographical area used to resize operation areas of the Regional Units of IAGRO, communicate notifications of sanitary events, surveillance planning 
and records of sanitary activities, therefore, an Epidemiological Unit." The quadrant dimensions were ten square nautical miles $\left(10 \mathrm{NM}^{2}\right)$ or ten square geographic minutes (10'geographical'), corresponding to $342.99 \mathrm{Km}^{2}$ or 34299.0 hectares with a perimeter of $74,080 \mathrm{Km}$. The individual identification of the quadrants was carried out in the West-East and North-South direction using numbers, and the quadrants belonging to more than one municipality were identified using numbers followed by letters. Thus, the quadrants identified only by a number meant that they belonged to a single municipality; quadrants identified by a number and only one letter meant that they belonged to more than one municipality, and hence were fractionated; and quadrant identified by a number and more than one letter meant that this fractional quadrant was added to the destination municipality by resizing. The state of MS was divided into 1215 quadrants and the municipality of Campo Grande into 34 quadrants.

The third stage consisted of geographical resizing of IAGRO's Regional Units in MS, due to the differences in extensions of geographical areas and the location of headquarters of the Local Units. A map of MS was edited with the quadrants' distribution in the West-East and North-South directions, identifying each quadrant individually. For this purpose, a 1/10000 scale digital map of operation areas of IAGRO's Regional Units in MS was created using the GPS TrackMaker ${ }^{\circledR}$ program, with quadrants individually identified to perform geographical resizing.

After quadrants on the map were delineated, a protocol was established for selecting quadrants to be resized geographically, with technical criteria for their selection in the order of sanitation and economic importance pre-defined as follows:

1- Time taken to attend sanitary events.

2- Distance from the Quadrant to the Local Unit headquarters.

3- Access roads (asphalt, sand, river, or air).

4- Type of access (car, boat, or airplane).

5- Sanitary Interest of the Local Unit (important region, strategic or technical affinity).

The spatial distribution of MS in quadrants was elaborated based on the provisions of ORDINANCE/IAGRO/MS No. 3589 of February 26, 2018, which established the areas of operation of Regional and Local Units.

In the fourth stage, maps were edited, and activities and communications were recorded. It is the operational mode for searching PIS; creating spreadsheet files, maps, and images; recording the activities performed and communication established, and allowing the planning, execution, monitoring, and control of sanitary actions.

In the fifth stage, the quadrant-based animal health surveillance protocol was defined. The basic planning of activities followed the following pattern: considering that one year has 52 weeks and the goal is to visit 3 quadrants per week, by the end of the year, 156 quadrants are to be visited. Each Local Unit divided the goal of visiting 156 quadrants by the number of quadrants defined in that Unit to determine how many visits to each quadrant should be made per year. It was defined that at least 3 surveillance actions would be performed in each quadrant, totaling 468 surveillance actions per local unit each year, without considering the quadrant's risk analysis.

Thus, all quadrants should be visited during the current year. All geographical areas of all Local Units must have records of the surveillance actions distributed evenly, ensuring the mandatory presence of the sanitary defense service in forgotten and/or unsupervised areas, at regular intervals, according to the sanitary risk.

For effective surveillance, it was considered ideal to visit 7 quadrants a week. The choice of 3 days a week to visit the quadrants enabled the responsible public servant to meet other demands of the Local Unit, and to keep the record of the services performed.

Fifty-two is the same number of weeks as in the Continental Epidemiological Surveillance System (SivCont) of MAPA and the Epidemiological Weeks Calendar. Therefore, the calendar of visits to the quadrants is linked to the Epidemiological Weeks Calendar. A minimum of 3 surveillance actions per visit to the quadrant, without risk analysis, were considered feasible.

The risk characterization of quadrants was defined as per characterization of quadrants was defined as per ORDINANCE for each sanitation program developed in MS. Hence, the requirements for the quadrants' risk classification are:

\section{1 - High Sanitary Risk Quadrants:}


- Located on the international border;

- Presence of animal agglomeration establishments (lasso clubs, auctions, exhibition parks, transit rest stations, etc.);

- Livestock exploitation within rural settlements, villages, and Quilombos;

- Situated on the outskirts of town and village;

- Presence of agricultural and cattle raising industries such as slaughterhouses, dairies, feed factories, warehouses of agricultural and cattle raising products;

- Presence of dumps or landfills;

- Presence of facilities for the disembarkation of passengers and cargo (rail, road, ports, airports); and

- Existence of laboratories authorized to handle infectious material.

2 - Medium Sanitary Risk Quadrants:

- Non-existence of items defined in High Sanitary Risk Quadrants;

- Livestock confinement;

- Presence of cattle roads and milk collection lines;

- Economic exploitation of various susceptible species;

- Intense flow of movement of susceptible animals;

- Economic activities involving great movement of vehicles;

- More than fifty rural properties per quadrant; and

- Presence of sheep resting properties for slaughter.

3 - Low Sanitary Risk Quadrants:

- Non-existence of items defined in Medium Sanitary Risks Quadrants; and

- Up to fifty farms per quadrant.

It is understood that the risk classification of a quadrant where different sanitary programs are developed is dynamic. According to the quantity and quality of the information gathered, a quadrant's degree of risk may increase or decrease. Therefore, the Local Inspector, together with the Regional Inspector, analyzes the information content of each quadrant, classifying the sanitary risk degree of the quadrants and defining the activities to be performed:

1-If properties with similar economic activities are found, but they are not associated with other risk factors (movement extract analysis and event history), at least 2 trips per quadrant are conducted, totaling 6 surveillance actions/year/quadrant.

2 - If, in the analyzed quadrant, there are rural settlements and/or groupings of small properties, the frequency of trips to these quadrants is maintained according to the general rule above, else the frequency increases. For each visit, a minimum of 3 surveillance actions are performed (settlement, groupings of small properties), and for properties without these characteristics, 2 more surveillances are performed on the same day.

3 - In quadrants with varied economic activities and sanitary risks, if the frequency of visits according to the general rule is considered insufficient, the number of trips left of low risk quadrants can be used to meet the demand.

4 - The fulfillment of goals depends on the information gathered from the quadrants to be visited during a month.

5 - The Low Sanitary Risk quadrants should be visited half-yearly or quarterly; the Medium Sanitary Risk quadrants quarterly or bimonthly, and the High Sanitary Risk quadrants bimonthly or monthly, depending on the number of visits defined by the Local and Regional Inspectors.

6 -If due to the nature of the services performed on that day, it is not possible to meet the minimum target, which would be 3 to 5 surveillances per day, the reason is justified, confirming through the GPS registration. For example: herd count, collection of biological material, capturing the hematophagous bats, inspection and monitoring of vaccines, etc. The use of a GPS receiver is compulsory in all sanitary defense service activities.

7 - Once the number of visits per quadrant and per Unit are defined by the Regional and Local Inspectors, it is not necessary to use the total number of visits allowed per year to low risk quadrants. Instead, those visits can be used for quadrants with higher sanitary risk. When possible, avoid visiting the same properties. 
8 - When a Local Unit receives a quadrant that includes areas of more than one municipality, the surveillance should cover all the municipalities of that quadrant and not only the original area of the Local Unit.

The Regional Inspector along with the Local Inspector:

- defines the degree of annual sanitary risk that each resized quadrant represents. The analysis and risk classification of the quadrants are performed using the available resources such as maps, images, and historical data of sanitation events; hence, creating the quadrant's epidemiological profile (Chart 1 and Figure 1).

- defines the annual number of planned visits to the resized quadrants. When drawing up the spreadsheet for quadrant visits, planning begins with the distribution of high-risk quadrants, followed by medium-risk, and finally low-risk quadrants. In the medium- and low-risk quadrants, the distribution is the constant 52 (number of epidemiological weeks) divided by the number of visits to the quadrant, with respect to the interval of the surveillance protocol. When the number of visits to high-risk quadrants is more than 12 per year, the surplus is distributed among the campaign and post-vaccination seasons. When possible, the weekly visits are divided between high-risk, medium-risk, and low-risk quadrants (Chart 2).

- prepares the annual kilometrage plan for surveillance actions in the resized quadrants, using as measurement parameter the distance between the Local Unit headquarter and the center of the quadrant, adding another $20 \mathrm{~km}$ to the final distance (Chart 3).

- prepares the quarterly plan of personnel expenditure for travel to the resized quadrants (Chart 4). The operational and surveillance actions in the quadrants were conducted following a predefined "service order," prepared at the Local Unit headquarters using the information regarding the annual planning of weekly quadrant visits (Chart 2).



Figure 1. Sanitary Risk Classification in the quadrants of the Campo Grande Municipality. Legend: 1- Green color = low risk quadrants, yellow color = medium risk quadrants, and red color = high risk quadrants; 2 - The code inside the green text box indicates that the quadrant belongs to the municipality and the red icon ( $(\mathbf{t})$ indicates that the quadrant belongs to another municipality whose resizing added it to this municipality; 3 - The red grid quadrants with white background were reallocated to other municipalities by resizing. 
Chart 1. Annual Risk Classification, Number of Visits, and Number of Animal Health Surveillance Actions by Quadrants of Campo Grande Municipality.

\begin{tabular}{|c|c|c|c|c|}
\hline \multicolumn{3}{|c|}{ Quadrant (identification) } & \multicolumn{2}{|c|}{ Quadrant Activities } \\
\hline High risk & Medium risk & Low risk & No of Visits/Year & No of Surveillance Acts/Year \\
\hline & 608B & & 3 & 9 \\
\hline \multirow[t]{2}{*}{ 609B } & & & 8 & 40 \\
\hline & $610 \mathrm{~B}$ & & 6 & 18 \\
\hline $652 \mathrm{~B}$ & & & 10 & 50 \\
\hline 653 & & & 8 & 40 \\
\hline \multirow[t]{2}{*}{ 654B } & & & 6 & 30 \\
\hline & & $655 \mathrm{C}$ & 1 & 3 \\
\hline 694B & & & 8 & 40 \\
\hline \multirow[t]{5}{*}{695} & & & 10 & 50 \\
\hline & 696 & & 4 & 12 \\
\hline & & 697B & 3 & 9 \\
\hline & & $733 \mathrm{~B}$ & 1 & 3 \\
\hline & & 734B & 4 & 12 \\
\hline \multirow[t]{5}{*}{735} & & & 6 & 30 \\
\hline & 736 & & 6 & 18 \\
\hline & & $737 \mathrm{AB}$ & 3 & 9 \\
\hline & & 738AB & 3 & 9 \\
\hline & & 773A & 2 & 6 \\
\hline \multirow[t]{10}{*}{ 774AB } & & & 6 & 30 \\
\hline & 775 & & 6 & 18 \\
\hline & 776 & & 6 & 18 \\
\hline & & 777AB & 2 & 6 \\
\hline & & 778AB & 2 & 6 \\
\hline & $814 \mathrm{AB}$ & & 6 & 18 \\
\hline & & $815 \mathrm{~A}$ & 4 & 12 \\
\hline & & 816 & 3 & 9 \\
\hline & & 817AB & 2 & 6 \\
\hline & & $818 \mathrm{AB}$ & 2 & 6 \\
\hline $853 \mathrm{~A}$ & & & 12 & 60 \\
\hline \multirow[t]{5}{*}{854} & & & 6 & 30 \\
\hline & & 855 & 2 & 6 \\
\hline & & $856 \mathrm{~B}$ & 3 & 9 \\
\hline & & 857B & 1 & 3 \\
\hline & & $890 B$ & 1 & 3 \\
\hline \multicolumn{5}{|c|}{ Total } \\
\hline 10 & 7 & 17 & 156 & 628 \\
\hline
\end{tabular}

The "service order" is prepared using the available resources of the e-SANIAGRO program, maps and images, the PIS and access ways; thus, defining the surveillance actions to be performed. The "service order" is then transferred to the GPS receiver or GPS application for real-time navigation and recording. The real-time navigation starts and ends at the Local Unit headquarters, recording the entire data enroute. The Local Unit can communicate the probable date of IAGRO team's visits to rural owners whose properties are along the predefined route, making it easier to carry out surveillance actions. 
Chart 2. Annual Planning of Quadrant Visit in Campo Grande Municipality.

\begin{tabular}{|c|c|c|c|}
\hline Epidemiological Week & Quadrant & Quadrant & Quadrant \\
\hline 1 & 696 & 734B & 815A \\
\hline 2 & 853A & 608B & 697B \\
\hline 3 & 610B & 654B & 735 \\
\hline 4 & 736 & $774 \mathrm{AB}$ & 814AB \\
\hline 5 & 775 & 854 & 776 \\
\hline 6 & $853 \mathrm{~A}$ & 652B & 695 \\
\hline 7 & 609B & 653 & 694B \\
\hline 8 & 737AB & 856B & 816 \\
\hline 9 & 738AB & $773 A$ & 777AB \\
\hline 10 & $853 \mathrm{~A}$ & 652B & 695 \\
\hline 11 & 778AB & 817AB & 855 \\
\hline 12 & 610B & 654B & 735 \\
\hline 13 & 609B & 653 & 694B \\
\hline 14 & 853A & 652B & 695 \\
\hline 15 & 736 & 774AB & $814 \mathrm{AB}$ \\
\hline 16 & 775 & 854 & 776 \\
\hline 17 & 696 & 734B & $815 A$ \\
\hline 18 & $853 \mathrm{~A}$ & 652B & 695 \\
\hline 19 & 818AB & 608B & 697B \\
\hline 20 & 609B & 653 & 694B \\
\hline 21 & 610B & 654B & 735 \\
\hline 22 & $853 \mathrm{~A}$ & 652B & 695 \\
\hline 23 & 736 & $774 \mathrm{AB}$ & 814AB \\
\hline 24 & 775 & 854 & 776 \\
\hline 25 & $738 \mathrm{AB}$ & $655 C$ & 733B \\
\hline 26 & 609B & 653 & 694B \\
\hline 27 & $853 A$ & 652B & 695 \\
\hline 28 & 737AB & 856B & 816 \\
\hline 29 & 610B & 654B & 735 \\
\hline 30 & 696 & 734B & $815 A$ \\
\hline 31 & $853 \mathrm{~A}$ & 652B & 695 \\
\hline 32 & 736 & $774 \mathrm{AB}$ & 814AB \\
\hline 33 & 609B & 653 & 694B \\
\hline 34 & 775 & 854 & 776 \\
\hline 35 & $853 \mathrm{~A}$ & 652B & 695 \\
\hline 36 & 778AB & 817AB & 855 \\
\hline 37 & $773 A$ & 777AB & 857B \\
\hline 38 & 610B & 654B & 735 \\
\hline 39 & 609B & 653 & 694B \\
\hline 40 & $853 A$ & 652B & 695 \\
\hline 41 & 736 & 774AB & 814AB \\
\hline 42 & 775 & 854 & 776 \\
\hline 43 & 696 & 734B & $815 \mathrm{~A}$ \\
\hline 44 & $853 \mathrm{~A}$ & 652B & 695 \\
\hline 45 & $738 \mathrm{AB}$ & 608B & 697B \\
\hline 46 & 609B & 653 & 694B \\
\hline 47 & 610B & 654B & 735 \\
\hline 48 & 737AB & $856 B$ & 816 \\
\hline 49 & 736 & 774AB & 814AB \\
\hline 50 & $853 A$ & 818AB & 890B \\
\hline 51 & 609B & 653 & 694B \\
\hline 52 & 775 & 854 & 776 \\
\hline
\end{tabular}


Chart 3. Annual kilometrage plan for surveillance actions in the Campo Grande Municipality/MS, according to quarters of 2018.

\begin{tabular}{|c|c|c|c|c|c|c|c|}
\hline $\mathbf{1}^{\text {st }}$ Quarter & Week & $\mathbf{2}^{\text {nd }}$ Quarter & Week & $\mathbf{3}^{\text {rd }}$ Quarter & Week & $\mathbf{4}^{\text {th }}$ Quarter & Week \\
\hline 419,4 & 1 & 353,2 & 14 & 353,2 & 27 & 353,2 & 40 \\
\hline 483,6 & 2 & 417,2 & 15 & 738 & 28 & 417,2 & 41 \\
\hline 231,4 & 3 & 636 & 16 & 231,4 & 29 & 636 & 42 \\
\hline 417,2 & 4 & 419,4 & 17 & 419,4 & 30 & 419,4 & 43 \\
\hline 636 & 5 & 353,2 & 18 & 353,2 & 31 & 353,2 & 44 \\
\hline 353,2 & 6 & 538,2 & 19 & 417,2 & 32 & 458,2 & 45 \\
\hline 219,6 & 7 & 219,6 & 20 & 219,6 & 33 & 219,6 & 46 \\
\hline 738 & 8 & 231,4 & 21 & 636 & 34 & 231,4 & 47 \\
\hline 557 & 9 & 353,2 & 22 & 353,2 & 35 & 738 & 48 \\
\hline 353,2 & 10 & 417,2 & 23 & 815,6 & 36 & 417,2 & 49 \\
\hline 815,6 & 11 & 636 & 24 & 681 & 37 & 924 & 50 \\
\hline 231,4 & 12 & 417 & 25 & 231,4 & 38 & 219,6 & 51 \\
\hline 219,6 & 13 & 219,6 & 26 & 219,6 & 39 & 636 & 52 \\
\hline $\mathbf{5 6 7 5 , 5}$ & -- & $\mathbf{5 2 1 1 , 2}$ & -- & $\mathbf{5 6 6 8 , 8}$ & -- & $\mathbf{6 0 2 3}$ & - \\
\hline
\end{tabular}

Chart 4. Annual planning of the number of per diem for the development of surveillance actions in the Campo Grande Municipality/MS, according to quarters of 2018.

\begin{tabular}{|c|c|c|c|c|c|c|c|}
\hline $\mathbf{1}^{\text {st }}$ Quarter & Week & $\mathbf{2}^{\text {nd }} \mathbf{Q u a r t e r}$ & Week & $\mathbf{3}^{\text {rd }}$ Quarter & Week & $\mathbf{4}^{\text {th }}$ Quarter & Week \\
\hline 3,4 & 1 & 3,4 & 14 & 3,4 & 27 & 3,4 & 40 \\
\hline 3,8 & 2 & 3,6 & 15 & 4,2 & 28 & 3,6 & 41 \\
\hline 3 & 3 & 4 & 16 & 3 & 29 & 4 & 42 \\
\hline 3,6 & 4 & 3,4 & 17 & 3,4 & 30 & 3,4 & 43 \\
\hline 4 & 5 & 3,4 & 18 & 3,4 & 31 & 3,4 & 44 \\
\hline 3,4 & 6 & 4 & 19 & 3,6 & 32 & 3,8 & 45 \\
\hline 3,2 & 7 & 3,2 & 20 & 3,2 & 33 & 3,2 & 46 \\
\hline 4,2 & 8 & 3 & 21 & 3,8 & 34 & 3 & 47 \\
\hline 4 & 9 & 3,4 & 22 & 3,4 & 35 & 4,2 & 48 \\
\hline 3,4 & 10 & 3,6 & 23 & 4,4 & 36 & 3 & 49 \\
\hline 4,4 & 11 & 4 & 24 & 4,2 & 37 & 4,6 & 50 \\
\hline 3 & 12 & 3,4 & 25 & 3 & 38 & 3,2 & 51 \\
\hline 3,2 & 13 & 3,2 & 26 & 3,6 & 39 & 4 & 52 \\
\hline $\mathbf{4 6 , 6}$ & -- & $\mathbf{4 5 , 6}$ & -- & $\mathbf{4 6 , 6}$ & -- & $\mathbf{4 6 , 8}$ & -- \\
\hline
\end{tabular}

The GPS receiver and/or GPS application is compulsorily used in all sanitation defense service activities. The operational and surveillance actions executed in the quadrants are registered in proper form by the GPS receiver. After the team returns from the field, the recorded data is transferred to the GPS TrackMaker ${ }^{\circledR}$ program, and is saved in folders in the Local Unit computer. The files have records of locations visited, routes traveled, and time spent on each surveillance activity.

The Local Inspector then builds different types of thematic maps of the municipality that are sent to the Regional Inspectorate in GTM digital file format, such as: Municipality General Map, Register of Monthly Activities Executed Map, thematic maps for all Sanitation Programs 
with demands in the Local Unit, Risk Areas Map, and Municipality Productive and Economic Characterization Map.

The Regional Inspector audits the Local Units on a monthly basis, considering the fulfillment of planned visits to the quadrants, through a specific form together with the GTM file of the "record of activities performed monthly."

The IAGRO CENTER OF OPERATIONS AND CONTROL, created by the Information Technology sector, files, records, alerts, monitors, controls, and subsidizes the operational actions, and the Database thus created is accessed exclusively by the authorized servers.

The Database is fed and updated periodically at monthly, semiannual, or annual intervals according to the information made available by the Local Units to Regional Units and from Regional Units to the Central Unit.

For map construction, the Standardization Manual for IAGRO Thematic Maps Edition was used in the GPS TrackMaker ${ }^{\circledR}$ program available in GED/IAGRO.

The information in the database is used to perform risk analysis in each quadrant, to plan inspection sites and activity types to be developed, to define the routes to be traveled, to calculate fuel and per diem, and to monitor and audit the activities performed.

\section{Results and discussion}

The pilot project of the Quadrant-based Animal Health Surveillance system was carried out at the Campo Grande Local Unit from $3^{\text {rd }}$ to $47^{\text {th }}$ epidemiological week of 2018. A team from IAGRO's Local Unit, comprising two public servants, a veterinarian and a companion, a vehicle, and a GPS receiver, visited 378 rural properties during this time; and the services by demands or routines executed by other Public servers from the Local Unit in Campo Grande.

A total of 630 visits were made to rural properties. However, before the project's implementation in 2018, areas of risk were not classified in the municipality. Surveillance actions were carried out to meet certain sanitary program goals and that too only in areas with cases of proven sanitary events.

Thus, to meet the health program goals, surveillance actions were carried out in easily accessible places, close to the municipality headquarters, with the same properties visited regularly. This type of surveillance is called "grape cluster surveillance or centered (concentrated) surveillance".

The record of the surveillance actions executed was based only on the superficial notes of the executors, and often did not contain enough information required for the audit.

The municipality of Campo Grande in 2017 carried out 402 reports on animal health surveillance actions on rural properties, using the above mentioned surveillance models.

Figure 2 shows a schematic representation of the Municipality of Campo Grande with records of surveillance actions carried out in 2017 (2A) and 2018 (2B). It can be observed that, in 2017, the surveillance actions were carried out in a non-uniform manner, concentrated around and at distances closer to the Local Unit, characterizing what is called the "grape cluster surveillance" with the specific purpose of meeting sanitary programs goals. Most of the surveillance actions were carried out in same areas, located closer to each other, with few or no surveillance actions carried out in more distant municipality areas.

In 2018, after the implementation of the new surveillance system, it was observed that the surveillance actions were carried out homogeneously throughout the Municipality of Campo Grande. The entire process was transparent with records kept of trails, day, time, routes and distances traveled, places visited, travel time duration and time spent on each surveillance action, and the maximum, average, and minimum speed of the vehicle at any location along the route.

Thus, the new system of Animal Health Surveillance by Quadrants brought many positive changes in the agricultural defense activities in the State of MS. Some of these changes are as follows:

1. The risk area classification that used to be carried out after the notification and confirmation of a health event, is now carried out beforehand using the available information, and is updated during physical visits to the quadrants. The representative unit for risk assessment is no longer the rural property but the quadrant's geographical area. 

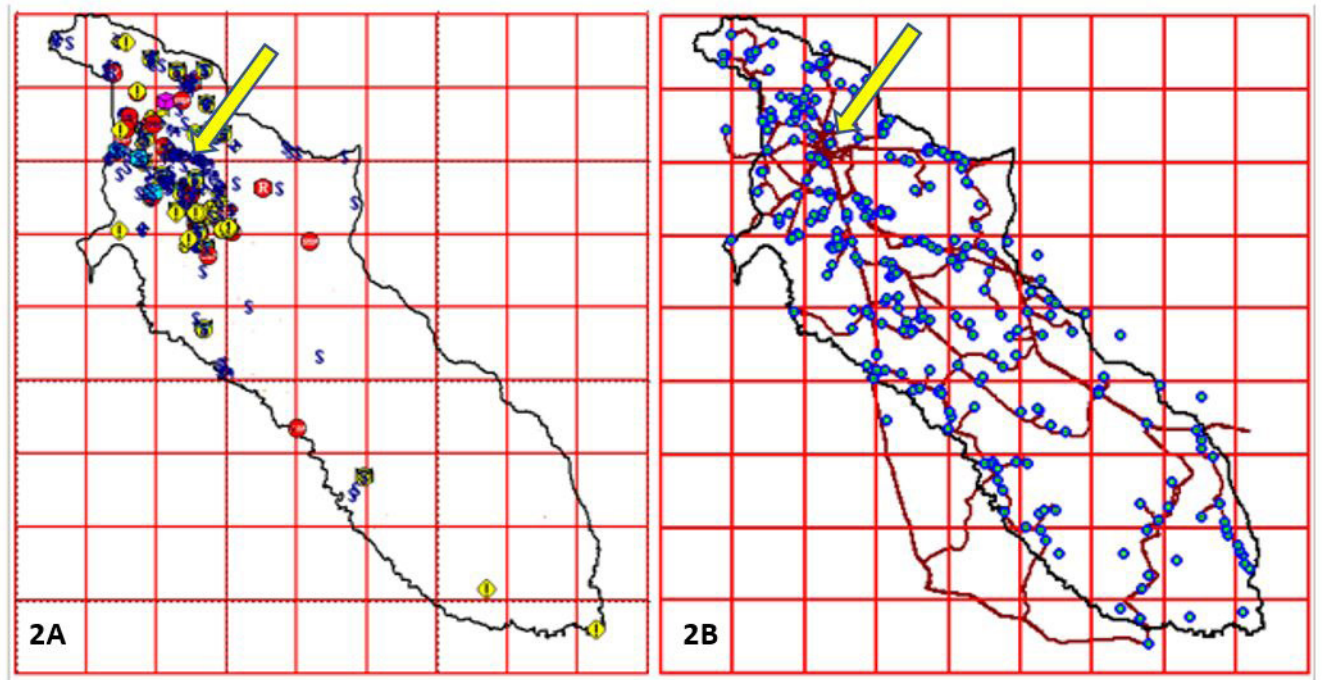

Figure 2. Schematic representation of Campo Grande Municipality with the records of surveillance actions carried out in 2017 (2A) and 2018 (2B). Legend: The different colored icons in Figure 2A represent the properties inspected according to different sanitary programs (PNEFA, PNSS, etc.); yellow arrow represents the headquarter location of IAGRO's LOCAL Unit at Campo Grande; blue icons in Figure 2B represent the inspected rural properties in the quadrant and the brown lines indicate records of distance trails in the inspection actions of quadrants.

2. The new system led to the optimization of active surveillance and consequently the rationalization of operating costs to execute field actions. Earlier, a single surveillance action was carried out for each property visit; now, 3 to 5 surveillance actions are carried out for each quadrant visit.

3. It was observed that $95 \%$ of the inspected properties did not undergo periodic surveillance by the health defense services. The new system led to the updation of sanitation records containing valid geographic coordinates and maps, trails, contact information, access routes, and sanitation and economic characteristics of the Local Units.

4. Using the updated information, planned actions in all MAPA health programs were carried out.

5. There has been a considerable increase in findings of non-conformities of properties without registration in the e-SANIAGRO program, the number of animal registrations, and notifications of possible diseases.

6. Health inspections were not interrupted or delayed with the help of anticipated operational planning with provision of resources.

7. It was possible to audit the performed actions quickly with transparency and reliability.

Thus, a considerable increase in the number of measures taken to remedy irregularities recorded in field actions was noted.

Of the total planned quadrant visits, $45.3 \%$ visits were made to the high-risk quadrants, $29.34 \%$ to the medium-risk quadrants, and $25.36 \%$ to the low-risk quadrants. This difference in the frequency of visits to quadrants with different sanitary risks increases the probability of detecting imminent risks of a sanitary event by rationalizing the operational costs to execute field actions. During visits to the quadrants, 18612 cattle, 180 pigs, 546 sheep, and 17 goats were inspected as part of planned surveillance actions.

The improvement in the quality of surveillance actions was remarkable. Available technologies along with innovative methodologies were used to geographically resize IAGRO's Regional Units, and to create maps, images, and spreadsheets, and hence plan the annual surveillance activities, operating costs, sanitary inspections of rural properties, including the execution and audit schedule, as well as recording all these activities in real time.

Thus, the annual planning and monitoring of all stages of animal health surveillance, from editing of maps to registration and auditing has become feasible. Health surveillance service registration are conducted in a fast and efficient way, and is easy to access, allowing for transparency and trust that are required by the inspection agencies. The simple operational mode allows the execution of actions by any competent public servant in any Local Unit of IAGRO. The beforehand selection 
of defense services in response to the sanitary events in Local Units by means of technical protocols, has made the process time and cost efficient.

The new model of health surveillance is now carried out in a more planned manner with the use of new methodology, covering the entire state region and all health programs.

\section{Conclusions}

Among the various advantages of the new Animal Health Surveillance by Quadrants system, some are as follows: all rural properties and other PIS existing in the quadrants form a unique database of IAGRO (with regular updation of property registration); identification of all types of existing activities and consequently the existing risks in the region; identification of access routes to optimize distance, time of service, and efficiency in monitoring traffic; supply of information to plan surveillance activities; providing information to plan human and financial resources; recording and monitoring all health surveillance activities; allowing IAGRO's public servants to plan surveillance activities in any Local Unit; providing tools for health surveillance, such as mapping, image, and navigation softwares; reducing time and costs for punctual attendance of health events; controlling personnel, per diem, and vehicle trails through the compulsory use of GPS receiver; and defining strategies and action plans in all IAGRO administrative areas.

The project "animal health surveillance by quadrants, intelligent planning and execution" improved the protocols of health care, with homogeneous geographic distribution of care, performed as active surveillance, completely transparent and auditable, which allows planning, controlling, and monitoring of all operational actions of health defense services of a state, region, or country. If implemented, the new system will give a differential advantage to the Brazilian Health Defense Services.

\section{Acknowledgements}

The authors thank Daniel de Barbosa Ingold, President Director of IAGRO for his support in publishing the article and implementing the Quadrant Health Surveillance project throughout the State of MS; Luciano Chiochetta, former President Director of IAGRO for his support in developing and carrying out the project as well as allowing it to be implemented as a pilot project in the Local Inspectorate of Campo Grande; state agricultural inspectors Eder Arruda de Andrade Júnior and Viviane Müller Dantas, for pilot project implementation in the Local Inspectorate of Campo Grande; and state agricultural inspectors Marcelo Sebastião Marcondes de Souza, Silvio Ernesto Bess, Daniel Moreira Severo, and Joelson Agostinho de Oliveira.

\section{References}

Associação das Indústrias Exportadoras de Carne - ABIEC. (2019a). Brasil bate recorde mundial de exportação de carne bovina. ABIEC: Brasília. Recuperado em 10 de maio de 2019, de https://anba.com.br/ brasil-bate-recorde-mundial-de-exportacao-de-carne-bovina/

Associação das Indústrias Exportadoras de Carne - ABIEC. (2019b) Beef REPORT - Perfil da Pecuária no Brasil. ABIEC: Brasília. Recuperado em 10 de maio de 2019, de http://www.abiec.com.br/controle/uploads/arquivos/ sumario2019portugues.pdf

Brasil. (2006, 30 de março). Organiza o Sistema Unificado de Atenção à Sanidade Agropecuária, e dá outras providências (Decreto n0 5.741, de 30 de março de 2006). Diário Oficial da República Federativa do Brasil.

Brasil, Ministério da Agricultura, Pecuária e Abastecimento. (2013, 24 de setembro). Instrução Normativa no 50, de 24 de setembro de 2013. Altera a lista de doenças passiveis da aplicação de medidas de defesa sanitária animal, previstas no art. 61 do Regulamento do Serviço de Defesa Sanitária Animal, publicado pelo Decreto no 24.548, de 3 de julho de 1934. Diário Oficial da República Federativa do Brasil.

Brasil. Ministério da Agricultura, Pecuária e Abastecimento. Saúde Animal. Recuperado em 10 de maio de2019a, from http://www.agricultura.gov.br/assuntos/sanidade-animal-e-vegetal/saude-animal/saude-animal

Brasil. Ministério da Agricultura, Pecuária e Abastecimento. (2019b) Programa Quali-SV. Brasília. Recuperado em 10 de maio de 2019b, from https://www.gov.br/agricultura/pt-br/assuntos/sanidade-animal-e-vegetal/ saude-animal/qualidade-dos-servicos-veterinarios/qualidade-dos-servicos-veterinarios

Buzanovsky, L. P., Santos, A. G., \& Vazques, M. J. S. (2015). Sistemas de Información Geográfica (SIG) Aplicados a la Vigilancia Zoosanitaria. Biológico, São Paulo, 77(Supl. 3), 23-62. Recuperado em 10 de maio de 2019, from http://www.biologico.sp.gov.br/uploads/docs/bio/suplementos/v77_supl_3/resumos.pdf 
Eidt, M. J., Sá, M. E. P., Mcmanus, C. M., \& Melo, C. B. (2015). Interceptações de Produtos de Origem Animal em Fronteiras Terrestres no Brasil. Ciência Animal Brasileira, 16(3), 388-398. Recuperado em 10 de maio de 2019, from http://www.scielo.br/scielo.php?pid=S1809-68912015000300388\&script=sci_abstract\&tlng=pt

Mato Grosso do Sul. Secretaria de Estado de Meio Ambiente, Desenvolvimento Econômico, Produção e Agricultura Familiar. Agência Estadual de Defesa Sanitária Animal e Vegetal (2019a, 30 de maio). Estabelece critérios para a classificação das propriedades consideradas de maior risco sanitário para a introdução de doenças nos rebanhos do Estado do Mato Grosso do Sul e dá outras providências (Portaria no 3618, de 30 de maio de 2019). Campo Grande.

Mato Grosso do Sul. Secretaria de Estado de Meio Ambiente, Desenvolvimento Econômico, Produção e Agricultura Familiar. Agência Estadual de Defesa Sanitária Animal e Vegetal (2019b, 11 de dezembro). Instrução de Serviço DDSA no 008/2019 de 11 de dezembro de 2019. Estabelece procedimentos para a realização da classificação das propriedades consideradas de maior risco sanitário pelas Unidades Locais. Campo Grande.

Mingoti, R., \& Spadotto, C. (2016). Gestão Territorial para Prevenir Novas Pragas. Revista Agroanalysis. 36(11), 24-25. Recuperado em 10 de maio de 2019, from http://www.agroanalysis.com.br/storage/2016/11/index. html\#page $=23$

Organização Mundial de Saúde Animal - OIE (2019). Vigilancia Sanitaria de los Animales Terrestres. Paris: OIE. Recuperado em 10 de maio de 2019, from http://www.oie.int/es/normas/codigo-terrestre/acceso-enlinea/?htmfile=chapitre_surveillance_general.htm 